\title{
Noncontrast and Perfusion CT Provides Accurate Assessment of Head Deceleration Injury
}

\author{
Kontrastsız ve Perfüzyon BT Beyin Deselerasyon Yaralanmasının Doğru \\ Değerlendirilmesini Sağlar
}

\author{
Rong $\mathrm{CHEN}^{1}$, Shao Xiang ZHANG ${ }^{2}$, Hui ZHAO ${ }^{3}$, Zhi Yong YIN³ ${ }^{3}$ jin Hua $\mathrm{CHEN}^{1}$, Wei Guo ZHANG ${ }^{1}$ \\ ${ }^{1}$ Third Military Medical University, Department of Radiology, Chongqing, China \\ ${ }^{2}$ Third Military Medical University, Department of Anatomy, College of Basic Medical Sciences, Chongqing, China \\ ${ }^{3}$ Third Military Medical University, State Key Laboratory of Trauma, Burns and Combined Injury, Department 4, Institute of Surgery \\ Research, Chongqing, China
}

Correspondence address: Wei Guo ZHANG / E-mail: wguo.zhang@gmail.com

\begin{abstract}
AIM:To investigate the feasibility of noncontrast computed tomography (NcCT) and perfusion CT (PCT) in the assessment of head deceleration injury (HDI).

MATERIAL and METHODS: A small animal HDI device was developed. A total of 20 healthy adult rabbits with frontal impacts resulting from a $3.5 \mathrm{~m}$ drop were included in this study. All subjects underwent NcCT and PCT scans 12 hours before injury and three to four hours after head injury. Brain injuries were evaluated by traditional macroscopic and microscopic examination after CT scans.

RESULTS: Microscopic examination revealed hemorrhagic cerebral contusions in 14 subjects and cerebral parenchyma hyperemia in 6 subjects. Contrecoup injuries were more severe than the coup injuries in this study. As verified by pathoanatomical observations, NcCT effectively revealed all of the calvarial fractures and basal skull fractures in 12 subjects. Furthermore, most rabbits suffered acute scalp contusions, subarachnoid hemorrhages and cerebral contusions. PCT analysis revealed much larger and more severe contusions when compared to those observed via NcCT.

CONCLUSION: The combination of NCCT and PCT could be an effective approach for detection of acute cerebral contusions, which can provide sufficient experimental evidence for accurate clinical diagnosis and prognosis of HDI.
\end{abstract}

KEYWORDS: Computed tomography, Traumatic brain injury, Fall from height, Deceleration

öz

AMAÇ: Beyin deselerasyon yaralanmasının (BDY) değerlendirilmesinde kontrastsız beyin tomografisinin ve perfüzyon BT nin uygulanabilirliğini araştırmak.

YÖNTEM ve GEREÇ: Küçük bir hayvan BDY cihazı geliştirildi. Bu çalışmaya 3.5 m'den düşme nedeniyle frontal darbeli toplam 20 sağlıklı erişkin tavşan dahil edildi. Bütün deneklere yaralanmadan 12 saat önce ve yaralanmadan 3-4 saat sonra kontrastsız beyin tomografisinin ve perfüzyon BT yapıldı. BT'lerden sonra beyin yaralanmaları geleneksel makroskopik ve mikroskopik incelemelerle değerlendirildi.

BULGULAR: Mikroskopik inceleme 14 denekte hemorajik serebral kontüzyon ve 6 denekte serebral parankimal hiperemi gösterdi. Bu çalışmada kontkup yaralanmalar, kup yaralanmalardan daha şiddetliydi. Patoanatomik gözlemlerle de gösterildiği gibi kontrastsız beyin tomografisi 12 denekte bütün kalvaryal ve kafa tabanı kırıklarını gösterdi. Ayrıca tavşanların çoğunda akut skalp kontüzyonları, subaraknoid kanamalar ve serebral kontüzyonlar mevcuttu. Perfüzyon BT analizleri kontrastsız beyin tomografisi ile gözlenenlere kıyasla daha büyük ve daha ciddi kontüzyonlar gösterdi.

SONUÇ: Kontrastsız beyin tomografisinin ve perfüzyon BT'nin beraber kullanımı akut serebral kontüzyonların tespit edilmesinde etkin bir yol olabilir ve bu da BDY nin kesin klinik tanısının ve prognozunu için yeterli deneysel kanıt sağlayabilir.

ANAHTAR SÖZCÜKLER: Bilgisayarlı tomografi, Travmatik beyin yaralanması, Yüksekten düşme, Deselerasyon 


\section{INTRODUCTION}

Head deceleration injury (HDI) is defined as a head injury caused by the sudden deceleration of the moving head upon impact with a static object (1). Clinically, HDI occurs at a much higher incidence than acceleration (a sudden turn or force forward) head injury. Several studies have noted differences between acceleration head injury and HDI in regards to injury characteristics and biomechanical mechanisms. By using a hammer to induce a coup injury in a fresh skull, Shen analyzed impact loading and discovered a significant difference in acceleration and deceleration head injury (2). Shen proposed that acceleration head injury generates greater negative pressure (tensile stress) at the contrecoup site, while HDI generates greater pressure at the impact site but less negative pressure and less injury at the contrecoup site. Wang et al. (3) reported that acceleration head injury generates primary injury at the impact site due to space buffer and has a good prognosis. However, this study found that the head absorbed greater energy in HDI because of an immediate stop, which caused direct injury at the impact site and severe injury at the contrecoup site. HDI is predominantly caused by motor vehicle accidents or falls, which often result in high disability and mortality rates. Gaining a detailed understanding of the injury characteristics associated with HDI is of great importance in its diagnosis, therapy, and prognosis. Currently, there are many reports involving HDI obtained from traffic accidents and short-distance falls (4); however, systematic studies of HDI obtained in controlled settings with varying degrees of injury are lacking. For example, the fall distance, position of the head, and initial velocity were random in clinical patients.

Animal experiments with controlled degrees of injury are superior to clinical data for biomechanical analysis. Experimental models of traumatic brain injury (TBI) have been designed to closely mimic human TBI seen clinically and have contributed greatly to the understanding of traumatic mechanisms. Much research is focused on acceleration head injury, such as that seen in weight drop and fluid percussion studies (5); however, few HDI models have satisfactorily reproduced clinical HDI conditions. These conditions might be reproduced more successfully if the animal's head were fixed and if initial velocity was controlled and monitored. Tan et al. created an HDI animal model and reproduced several important clinical HDI findings in rabbits by utilizing an impactor consisting of a rotor, elastic strips, a platform, and a revolving board (6). Although this model was successful, the elastic strips lose their properties and wear over time, which could affect the intended injury.

Medical imaging techniques are important clinical tools in the management of TBI patients. In acute cranial trauma, computed tomography (CT) is typically the preferred method of diagnosis due to its availability, high speed, and high sensitivity for detection of injuries that require emergency neurosurgical intervention. It can determine the presence and extent of injury and can help guide surgical planning or minimally invasive interventions $(7,8)$. As an augmentation to conventional imaging techniques, functional imaging is applied to manage brain trauma (9). Perfusion CT (PCT) using contrast agents can access vascular physiology and improve TBI diagnosis (10); however, few studies have evaluated PCT for detection of cerebral contusions accompanying noncontrast $\mathrm{CT}$ (NCCT) scans in the acute injury phase of patients (11). In our study, we constructed a device to simulate HDI in a rabbit model and used NCCT and PCT to detect acute head injury. Imaging findings were validated using microscopic techniques in order to provide experimental evidence for accurate clinical diagnosis and prognosis of HDI.

\section{MATERIAL and METHODS}

\section{Small Animal HDI Device}

A self-developed, small animal HDI device was used to reproduce HDI after a fall (patent obtained). The HDI device was composed of six parts: bases, sliding guide bracket, sled, frame, impact platform, and buffered cushion (Figure 1A-G). The impact platform was made of steel. Its shape was that of a sphere corona, $18 \mathrm{~mm}$ high and $30 \mathrm{~mm}$ in diameter. Upper and lower bases were vertically mounted on the wall. Four steel wires with both ends fixed on the base were used to create a sliding guide bracket. The longest sliding

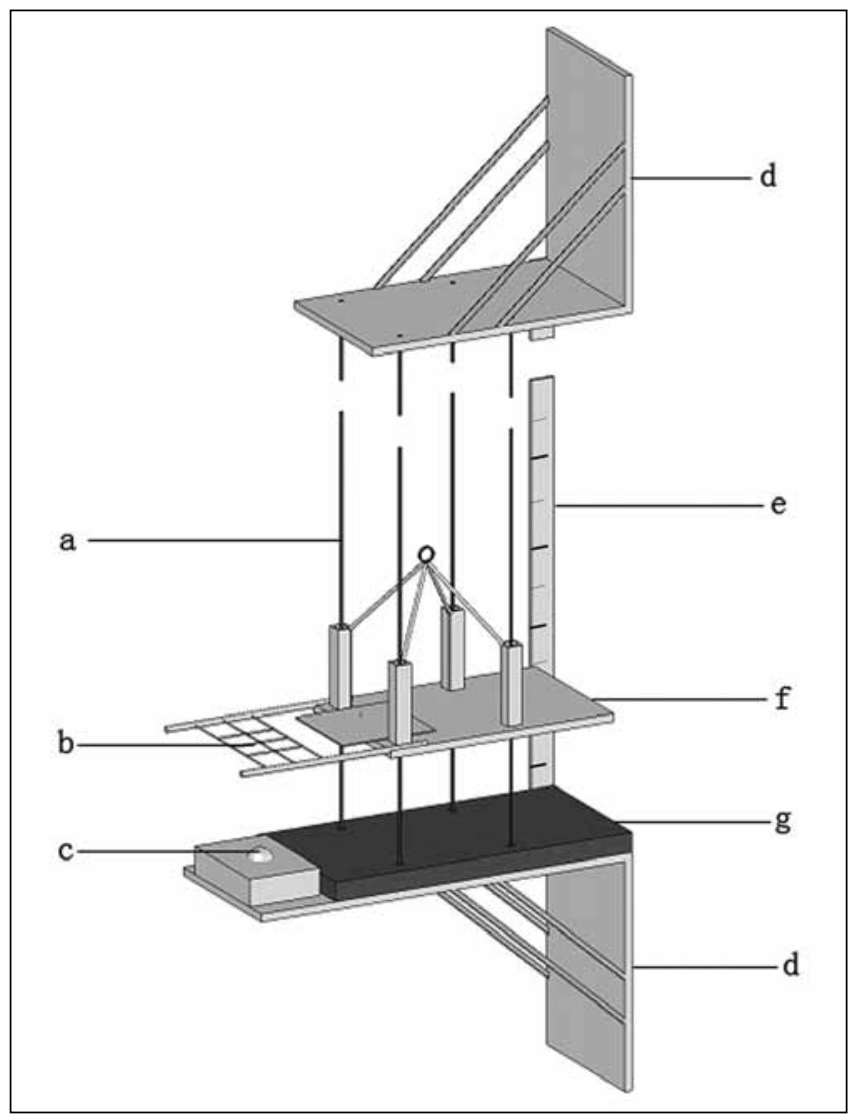

Figure 1: Small animal head deceleration injury device. A: sliding guide bracket; B: frame; C: impactor platform; D: bases; E: ruler; F: sled; G: buffered cushion. 
distance of the sled was $7.0 \mathrm{~m}$. Rolling bearings were installed surrounding the sled to support free perpendicular sliding. A buffered cushion was placed on the lower base, facing up, to retard the deceleration when the sled impacted the lower base. During the HDI process, the subject was fixed on the sled in the supine position and the head was held in place with polyester adhesive tape. A frame supported the subject's head with the impact site focused on the impactor platform; the sled was then elevated to the designated falling distance. After the drawing hook was released, the subject slid down with the sled and the subject's head impacted the impactor platform causing HDI.

\section{Animal Protocol}

Ethical approval was obtained prior to the commencement of the study from the Council on Animal Care and the Animal Use Subcommittee at our institute. The "Principles of Laboratory Animal Care" were followed, and all efforts were made to minimize suffering and the number of animals used. In preliminary experiments, the initial injury heights were defined as $2.5 \mathrm{~m}$ (light injury level), $3.5 \mathrm{~m}$ (moderate injury level), and $7.0 \mathrm{~m}$ (severe injury level). Each group underwent impact at four different head sites including occipito-parietal, temporo-parietal, parietal, and frontal sites.

For the four head impact sites, the $7.0 \mathrm{~m}$ drop group experienced the most severe injuries and all subjects died, mostly of persistent apnea. The $3.5 \mathrm{~m}$ drop group presented a large amount and multiple types of lesions including skull fracture, subarachnoid hemorrhage, and cerebral contusions, and presented typical injury characteristics of $\mathrm{HDI}$; the contrecoup injury in this group was more severe than the coup injury, with partial mortality. The $2.5 \mathrm{~m}$ drop group experienced the least severe head injuries with no visible injury in cerebral parenchyma and no mortality. As for head impact sites, within the same drop height group, the subjects with an impact site at the occipito-parietal region experienced the most severe injury and highest mortality rate; the subjects whose impact site was concentrated in the frontal region experienced moderate injury and had the highest survival rate. For PCT, the subjects needed to be alive and have normal respiration and heart rates in order for the contrast agent to reach the brain tissue. Based on preliminary data regarding the relationship between drop heights, rabbit head injury level, and survival rate, a frontal impact site was selected for this study and the selected drop height chosen was $3.5 \mathrm{~m}$.

The biomechanical data were obtained by digitally recording and calculating parameters of interest. Impact force was 800 $\mathrm{N}$ and impact speed was $8.0 \mathrm{~m} / \mathrm{s}$. The physiological responses of 24 experimental rabbits were monitored just after impact. 21 exhibited deep, fast breathing, 13 displayed pain reflex inhibition, 9 were found to have corediastasis, and 4 presented with urinary incontinence. Most of them recovered to a normal state 30 minutes after head injury. The survival rate of subjects was 100\%; however, 4 rabbits presented with weak respiration and heart rates during the CT scans and were excluded from the study. Ultimately, a total of 20 healthy, adult rabbits (male, 11; female, 9; weight range, 2.0$2.5 \mathrm{~kg}$; mean weight, $2.21 \pm 0.15 \mathrm{~kg}$ ) were included in the final analysis.

The subjects were fasted for four hours before the HDI experiment and anesthetized during the entire HDI experiment and subsequent $\mathrm{CT}$ scans. Anesthesia was induced by ear border venous injection of $3 \%$ pentobarbital sodium ( $30 \mathrm{mg} / \mathrm{kg}$ ), followed by anesthesia maintenance with intratracheal intubation. NcCT and PCT scans were performed in all subjects 12 hours before injury and three to four hours after head injury. Catheters were inserted in a posterior limb vein for the injection of contrast agent. After the CT scans were performed, the subjects were euthanized and macroanatomy was investigated using whole aspect and coronal sections of the scalp, skull, and brain tissues. Brain tissue specimens, including those from the impact and contrecoup site, were fixed in $10 \%$ buffered formalin. $3 \mu \mathrm{m}$ thick sections were stained with conventional hematoxylin and eosin (HE) and observed using light microscope (Olympusix70; Japan). Two investigators who were blinded to the imaging results independently performed analyses of pathoanatomical manifestations.

\section{CT imaging protocol and data processing}

All imaging studies were performed with a multi-detector CT scanner (64-slice LightSpeed; GE Medical Systems, USA) using the following parameters: $100 \mathrm{kVp}, 80 \mathrm{~mA}, 512 \times 512$ matrix sizes and $13-\mathrm{cm}$ field of view. The subject was positioned on the animal fixation bed in the supine position for coronal head CT scans. NcCT was performed at $0.625-\mathrm{mm}$ spiral scanning mode and $1.25-\mathrm{mm}$ axial scanning mode. Multiplanar reconstruction and 3D-volume rendering was applied in order to observe the skull fracture.

The PCT imaging protocol consisted of a 40-second series with 40 gantry rotations performed at a rate of 0.5 second per rotation in cine mode during posterior limb vein infusion of a bolus of $5 \mathrm{ml}$ iohexol (Omnipaque 350; Amersham Health, USA) at a rate of $0.5 \mathrm{ml} / \mathrm{sec}$ using a power injector. CT scan initiation was synchronized with contrast agent injection. PCT was acquired with serial, 40-mm-thick sections $(2.5-\mathrm{mm}$ slice thickness) from the anterior edge of the frontal cortex to the brain stem. PCT data were analyzed using PCT software (AW4.2; GE Medical Systems, USA). The internal carotid artery and superior sagittal sinus were selected as reference vessels, and the time-contrast enhancement curves registered in each pixel was created. Sixteen serial section false-color functional images were obtained, including cerebral blood flow maps $(\mathrm{CBF})$, cerebral blood volume maps (CBV), and mean transit time maps (MTT). Regions of interest (ROI) were placed on the impact site and contrecoup site with two ROls on each site. The size of each ROI was two to four pixels, avoiding large vessels or cerebrospinal fluid. NcCT and PCT images were independently analyzed by two neuroradiologists. Discrepancies between the neuroradiologists interpretations were jointly reviewed before a final agreement was reached. 


\section{Statistical analysis}

Statistical analysis was performed using SPSS software (SPSS 13.0, USA). CBF, CBV, and MTT values have been presented as mean \pm SD. Comparisons between the values of the different PCT parameters for the various $\mathrm{ROI}$ were analyzed using a paired-samples $T$ test. A difference with $p<0.05$ was considered significant.
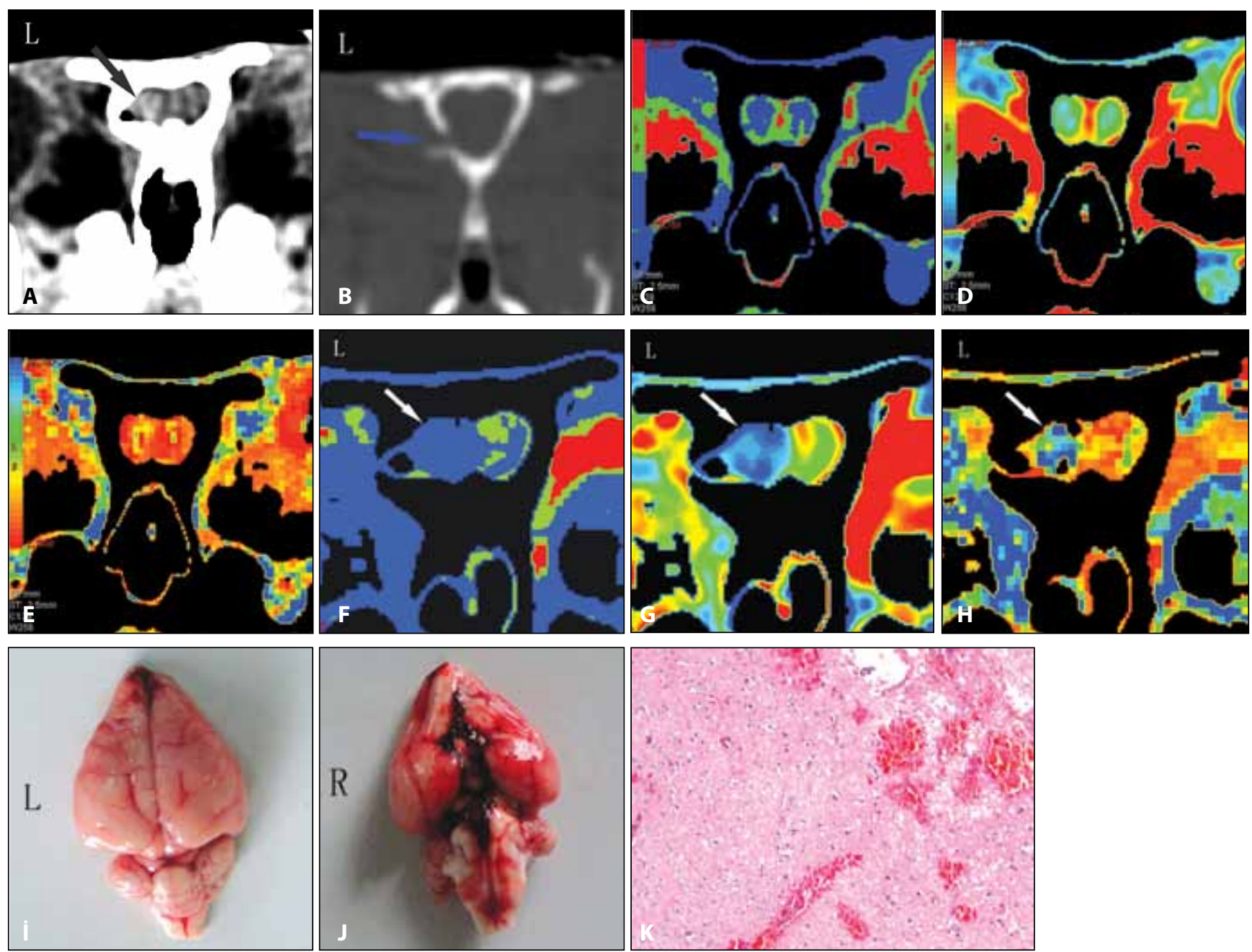

Figure 2: Findings from a rabbit weighing $2.3 \mathrm{~kg}$ after fall from $3.5 \mathrm{~m}$ with left frontal region as the impact site. A) Post-trauma coronal NcCT scan with cerebral parenchyma window depicts a small hemorrhagic focus in the left frontal lobe with pneumocephalus. B) Post-trauma coronal NcCT scan with skull window shows left frontal basal linear fracture. C, D, E) Coronal perfusion images of pretrauma. c: CBF; d: CBV; e: MTT. Normal frontal lobe PCT shows homogeneous effects on brain tissue with symmetric perfusion. F, G, H) Coronal perfusion images of post-trauma. f: $\mathrm{CBF}, \mathbf{g : ~} \mathrm{CBV}$; $\mathbf{h}$ : MTT. The PCT scan, however, shows a more extensive brain perfusion abnormality in the left frontal lobe than the hyperdense area on the NCCT. This area is characterized by low CBF, low CBV, and high MTT values. I, J) The gross pathological manifestation of the rabbit brain following injury. i: Superior surface; j: inferior surface. The coup injury is observed at left frontal lobe (impact site); contrecoup injury is found at ipsilateral basifrontal and bilateral frontal poles (contrecoup site, marked by black arrow), with the contrecoup injury being more severe than the coup injury. K) Representative photomicrograph of cerebral contusions at the bottom of frontal lobe. H\&E staining. Magnification 100x. Local brain tissue breakage, cerebral parenchymal hemorrhage, mild hyperemia and brain edema are shown. 
Table I: Twenty Rabbit Cerebral Injuries as Revealed by Pathology and CT (Presented as Number of Subjects)

\begin{tabular}{|c|c|c|c|c|c|c|c|c|}
\hline \multirow[t]{2}{*}{ Modality } & \multirow{2}{*}{$\begin{array}{l}\text { Scalp } \\
\text { contusion }\end{array}$} & \multicolumn{2}{|c|}{ Skull fracture } & \multirow{2}{*}{$\begin{array}{l}\text { Subdural } \\
\text { hematoma }\end{array}$} & \multirow{2}{*}{$\begin{array}{l}\text { Subarachnoid } \\
\text { hemorrhage }\end{array}$} & \multirow{2}{*}{$\begin{array}{l}\text { Cerebral } \\
\text { hyperemia }\end{array}$} & \multicolumn{2}{|c|}{$\begin{array}{l}\text { Cerebral } \\
\text { contusions }\end{array}$} \\
\hline & & Cranial & Basal & & & & Coup & Contrecoup \\
\hline Pathology & 18 & 9 & 12 & 4 & 15 & 6 & 8 & 14 \\
\hline $\mathrm{NcCT}$ & 14 & 9 & 12 & 1 & 9 & 0 & 5 & 10 \\
\hline PCT & 0 & 0 & 0 & 0 & 0 & 0 & 8 & 14 \\
\hline
\end{tabular}

Table II: CBF, CBV and MTT Values from PCT of 20 Rabbits

\begin{tabular}{l|c|c|c}
\hline Parameter & Pre-trauma & ${\text { Cerebral hyperemia }{ }^{\text {a }}}^{\text {Contusion }^{b}}$ \\
\hline CBF $(\mathrm{ml} / 100 \mathrm{~g}$ per $\mathrm{min})$ & $56.62 \pm 7.78$ & $47.27 \pm 12.40$ & $6.59 \pm 1.64$ \\
CBV $(\mathrm{ml} / 100 \mathrm{~g})$ & $2.81 \pm 0.56$ & $2.59 \pm 0.70$ & $0.74 \pm 0.21$ \\
MTT(s) & $3.26 \pm 0.68$ & $3.54 \pm 0.98$ & $10.92 \pm 2.99$
\end{tabular}

Paired-samples t test: Pre-trauma controls vs. cerebral hyperemia and contusion at the same location, for parameters CBF, CBV and MTT. ${ }^{a} p>0.05 ;{ }^{b} p<0.001$.
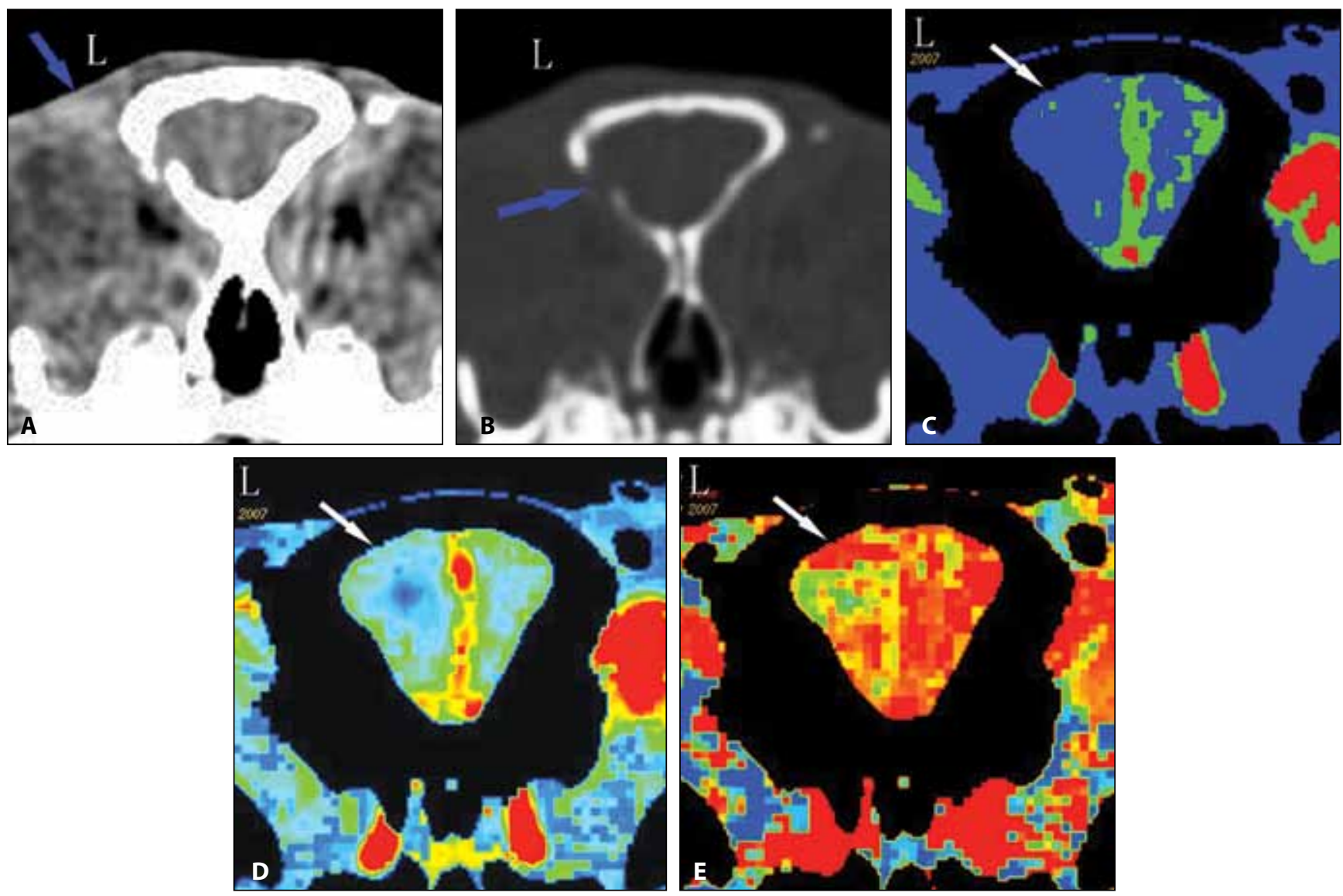

Figure 3: Findings from a rabbit weighing $2.1 \mathrm{~kg}$ after fall from $3.5 \mathrm{~m}$ with left frontal region impact site. A) Post-trauma NcCT scan with cerebral parenchyma window shows scalp contusion in left frontal region; no abnormal density is observed in the bilateral frontal lobe. B) Post-trauma NcCT scan with skull window shows left frontal basal fracture. C, D, E) Coronal perfusion images of post-trauma coronal PCT. c: CBF; d: CBV; e: MTT. PCT shows an acute brain perfusion abnormality at the bottom of the left frontal lobe (contrecoup site) that revealed a normal area on NCCT. In the contused areas, the CBF and CBV values are decreased while the MTT values are increased. 
scalp contusion and cranial fracture (mainly depressed and comminuted fracture) at the impact site and a basal fracture in the anterior fossa (mainly linear and comminuted fracture). When the impact site was on one side (as seen in nine rabbits), ipsilateral basal fractures appeared. When the impact site was in the middle (as seen in three rabbits), bilateral basal fractures appeared. A subdural hematoma was observed predominantly at the inferior surfaces of the temporal and frontal sites (contrecoup site). Subarachnoid hemorrhages were mainly found around the brainstem, the ventral aspect of the brain, and spread thinly over the contused areas. As for the cerebral parenchyma, two animals appeared normal; four appeared hyperemic in the bottom of the frontal lobes or in the bottom of the frontal and temporal lobes, and 14 presented cerebral contusions. Among the 14 cerebral contusions subjects, eight cerebral contusions occurred beneath the impact site of the frontal lobes (coup injury), and 14 cerebral contusions were observed at the inferior surfaces of temporal lobes and bilateral frontal poles (contrecoup injury). Overall, the contrecoup injuries were greater than the coup injuries. In coronal sections, cerebral contusions were found at the cortical and subcortical regions of brain.

Microscopic examination revealed hemorrhagic cerebral contusions in 14 subjects and cerebral parenchyma hyperemia in six subjects, including two rabbits that had been otherwise normal by macroscopic examination. In eight rabbits, in which coup injury occurred at the frontal lobes, HE staining revealed slight brain tissue breakage (five rabbits), cerebral parenchymal hemorrhage (eight rabbits), neuronal and astrocytic swelling (eight rabbits), perivascular space enlargement (six rabbits), meningeal hyperemia (eight rabbits), and mild brain edema (six rabbits). 14 rabbits exhibited cerebral contrecoup injury, which occurred at the inferior surfaces of temporal lobes and bilateral frontal poles; pathological findings were observed in all of these. In addition, brain tissue breakage and cerebral parenchymal hemorrhage were more prevalent and severe than in the frontal lobes, and the rupture of small vessels was also seen. No axonal injury was observed in areas where cerebral contusion occurred. In cerebral hyperemia areas, several congested capillaries were seen and no focal lesions or contusions were observed.

\section{NcCT Images}

The head injuries diagnosed using NcCT are listed in Table I. $\mathrm{NcCT}$ revealed all of the calvarial fractures (9/9) and basal skull fractures (12/12), most of the acute scalp contusions (14/18), subarachnoid hemorrhages (9/15), and cerebral contusions (5/8), when compared to pathological findings. Acute cerebral contusion appeared as a hyperdense lesion in $\mathrm{NcCT}$, which corresponded to pathoanatomical bleeding; hypodense regions in $\mathrm{NcCT}$ corresponded to pathoanatomical brain tissue breakage and edema. NcCT scans revealed HDI characteristics that matched the macroscopic observations (Figure 2A-K). However, mild scalp contusions, minor hemorrhages, mild cerebral contusions, and cerebral parenchyma hyperemia were negative on $\mathrm{NcCT}$.

\section{PCT Measurements}

Pre-trauma CBF, CBV, and MTT maps were homogeneous on brain tissue with symmetric perfusion in the bilateral cerebral hemisphere. CBF, CBV, and MTT values from the 20 rabbits with head PCT are summarized in Table II. PCT was successful as a diagnostic tool, as it revealed all of the acute cerebral contusions that occurred at the frontal lobes, the inferior surfaces of temporal lobes, and bilateral frontal poles (coup injury and contrecoup injury). All of these injuries were confirmed by our pathological findings. In coronal perfusion images of pre-trauma, all of the acute cerebral contusion-lesions were localized brain hypoperfusion and were characterized by decreased CBF and CBV values and increased MTT values compared with the values in pretrauma control areas $(t=49.535,25.692,17.183$, respectively; $p<0.001)$. All of the 14 cerebral contusion-lesions were shown to have the clearest border in CBV maps, which were larger than $\mathrm{NcCT}$ hyperdense regions (Figure 3A-E). However, scalp contusions, skull fractures, subdural hematoma, subarachnoid hemorrhage, and pure cerebral parenchyma hyperemia were not detectable in the PCT images. As verified by pathoanatomical observations, contused areas in PCT included pathoanatomical brain tissue breakage, bleeding, hyperemia, and edema regions; the combination of $\mathrm{NcCT}$ and PCT findings can more satisfactorily portray HDI pathological injury characteristics.

\section{DISCUSSION}

In this study, a small animal HDI device was developed to mimic short-distance falls, which are an important type of TBI seen clinically. The development of this experimental animal model was a key component primarily because it accurately reproduced clinical brain injuries. Live animal models preserve much of the complexity associated with human TBI while allowing for manipulation of parameters that are not possible in human studies. Such in vivo animal models allow for manipulation of cellular components and real-time measurement of acute responses (5). Current animal models of TBI can be broadly classified as follows: the impact acceleration model, the inertial (nonimpact) acceleration model, and the direct brain deformation model (12). Unfortunately, the characteristics and mechanisms of HDI are not well understood due to a lack of experimental studies. Using the small animal HDI device developed in this study, we were successful in reproducing and studying primary head traumas that had the typical features of HDI from falls. We found that contrecoup injury was more prevalent and severe than the coup injury (in agreement with (13)). Using our device, the subject was accelerated by free fall until the head impacted the impactor platform causing HDI. We approximated that the injury mechanism and injury characteristics in this animal model were similar to that seen clinically. Furthermore, the trauma revealed in this paper is consistent with that previously reported by Yanagida et al. (14). 
$\mathrm{NcCT}$ and PCT were used to detect the characteristics of HDI from falls in the study presented herein. $C T$ and magnetic resonance imaging (MRI) are the most frequently used imaging techniques to evaluate TBI features. Conventional MRI is more sensitive than a CT scan in detecting diffuse axonal injury and non-hemorrhagic contusions. Perfusion MRI is sensitive to microscopic tissue-level changes in cerebral blood volume (9). In the subacute phase of head injury, low cerebral blood volume in regions of focal pathology has been found in patients with contusions and edema is visible by conventional MRI (15). Limitations of the perfusion MRI technique, such as difficult quantification and limited application in the emergency setting, prevent it from being a widely adopted technique. CT scans of the head (which is available 24-hours a day in most hospitals, as well as providing the benefit of shorter imaging time) are the primary imaging technique for evaluating acute brain injury and are superior in evaluating bones and detecting acute subarachnoid or acute parenchymal hemorrhage $(7,8)$. More recently, the advent of fast multidetector $C T$ systems and the availability of commercial software for perfusion analysis have promoted the use of CT for functional brain imaging. PCT has been found to be useful for noninvasive evaluation of brain tissue microcirculation and is mainly used in the evaluation of cerebral ischemia stroke and infarction; however, few studies have focused on the application of PCT in patients with acute TBI $(16,17)$. Some studies have shown that PCT is more sensitive than conventional $\mathrm{NcCT}$ in the detection of cerebral contusions, and would provide independent prognostic information regarding functional outcome $(18,19)$.

Our results showed that $\mathrm{NcCT}$ revealed all of the calvarial fractures and basal skull fractures, most of the acute scalp contusions, subarachnoid hemorrhages and cerebral contusions when compared to pathological findings; however, mild scalp contusions, minor hemorrhages, mild cerebral contusions and cerebral parenchyma hyperemia were negative on NcCT. PCT revealed all of the acute cerebral coup and contrecoup contusions. In contused areas, the CBF and CBV values decreased and MTT values increased compared with the values in pre-trauma control areas. However, the pure cerebral parenchyma hyperemic areas lacked evident changes in CBF, CBV, and MTT images. It is possible that contusion is a key factor in the development of blood brain barrier permeability, after which a contrast agent can readily reach the brain tissue and produce changes in PCT images. Compared to $\mathrm{NcCT}$, PCT was more sensitive in the detection of acute cerebral coup and contrecoup contusions that had been identified in pathological findings and revealed contused areas that were larger than NcCT hyperdense regions. These imaging findings from rabbits show that PCT could be an effective approach for detection of acute cerebral contusions. However, scalp contusions, skull fractures, subdural hematoma, subarachnoid hemorrhage, and pure cerebral parenchyma hyperemias were not easily detected due to a lack of evident perfusion changes in PCT images. Therefore, TBI is unable to be accurately diagnosed by PCT imaging alone. By combining NcCT and PCT scans, HDI characteristics can be more satisfactorily assessed, which can provide experimental evidence for accurate clinical diagnosis and prognosis of $\mathrm{HDI}$. The positive correlation between pathology and $C T$ imaging of $\mathrm{HDI}$ can provide definite pathological evidence for $\mathrm{CT}$ diagnosis. CT findings such as scalp contusions, skull fractures, coup, and contrecoup lesions may provide important information for future in vivo HDI studies. In patients with mild-to-moderate head injury, conventional $\mathrm{NcCT}$ scans have limited usefulness in detecting structural and functional abnormalities, which may lag behind actual intracranial injury and underestimate brain injury (9). The changes in blood brain barrier and microcirculation are the earliest and most sensitive features presented after brain injury, which may be better delineated by PCT. For clinical, mild-to-moderate head injury in the acute phase of patients, a combined NCCT and PCT scan can be use to improve the accuracy of trauma injury diagnosis and provide more comprehensive information for HDI treatment and prognosis when NcCT findings and neurological symptoms are contradictory.

A limitation of this study is that only living subjects with normal respiration levels and heart rates underwent posttrauma PCT scans (i.e. only the frontal impact site of $3.5 \mathrm{~m}$ drop height was selected for this study). In future studies, the fall height and impact site will be adjusted for more accurate imaging evaluation. The subjects in this study were chosen so that they had similar body weights. This was done to remove the effect of variations in body weight. The relationship between biomechanical parameters and injury features has not yet been investigated in detail. Future studies may investigate speed changes of the rabbits head during impact using high speed video systems; force and pressure sensors may be placed inside and outside the rabbit's head to record loading during immediate impact, evaluate the pressure distribution, and calculate pressure wave propagation. These studies, when compared with CT findings, should help reveal HDI biomechanical mechanisms (20).

\section{REFERENCES}

1. Gaetz M: The neurophysiology of brain injury. Clin Neurophysiol 115:4-18, 2004

2. Shen Y: Analysis of dynamic stress for human skull-brain under impact loading with acceleration and deceleration. J Biomed Eng $17: 262-265,2000$

3. Wang SS, Jing JJ: Biomechanical mechanism of craniocerebral impact injuries. Journal of Fuzhou Central Hospital 9:205-207, 2002

4. Yagmur Y, Guloglu C, Aldemir M, Orak M: Falls from flat-roofed houses: A surgical experience of 1643 patients. Injury 35:425-428, 2004

5. LaPlaca MC, Simon CM, Prado GR, Cullen DK: CNS injury biomechanics and experimental models. Prog Brain Res 161: 13-26, 2007

6. Tan YF, Cao MH, Liu YS: A new model of decelerating head injury in rabbits. Chin J Traumatol 17:212-215, 2001 
7. Provenzale J: CT and MR imaging of acute cranial trauma. Emerg Radiol 14:1-12, 2007

8. Lee $B$, Newberg $A$ : Neuroimaging in traumatic brain imaging. NeuroRx 2:372-383, 2005

9. Metting Z, Rödiger LA., De Keyser J, van der Naalt J: Structural and functional neuroimaging in mild-to-moderate head injury. Lancet Neurol 6:699-710, 2007

10. Miles KA: Perfusion imaging with computed tomography: Brain and beyond. Eur Radiol 16: 37-43, 2006

11. Metting Z, Rödiger LA, Stewart RE, Oudkerk M, De Keyser J, van der Naalt J: Perfusion computed tomography in the acute phase of mild head injury: Regional dysfunction and prognostic value. Ann Neurol 66(6):809-816, 2009

12. Finnie JW, Blumbergs PC: Animal models: Traumatic brain injury. Vet Pathol 39:679-689, 2002

13. Drew LB, Drew WE: The contrecoup-coup phenomenon: A new understanding of the mechanism of closed head injury. Neurocrit Care 1:385-390, 2004

14. Yanagida Y, Fujiwara S, Mizoi Y: Differences in the intracranial pressure caused by a 'blow' and/or a 'fall'--an experimental study using physical models of the head and neck. Forensic Sci Int 41:135-145, 1989
15. Garnett MR, Blamire AM, Corkill RG, Rajagopalan B, Young JD: Abnormal cerebral blood volume in regions of contused and normal appearing brain following traumatic brain injury using perfusion magnetic resonance imaging. J Neurotrauma 18: 585-593, 2001

16. Miles KA: Brain perfusion: Computed tomography applications. Neuroradiology 46: 194-200, 2004

17. Hoeffner EG, Case I, Jain R, Gujar SK, Shah GV, Deveikis JP, Carlos RC, Thompson BG, Harrigan MR, Mukherji SK: Cerebral perfusion CT: Technique and clinical applications. Radiology 231:632-644, 2004

18. Wintermark $M$, Melle VG, Schnyder P, Revelly JP, Porchet $F$, Regli L, Meuli R, Maeder P, Chioléro R: Admission perfusion CT: Prognostic value in patients with severe head trauma. Radiology 232:211-220, 2004

19. Soustiel JF, Mahamid E, Goldsher D, Zaaroor M: PerfusionCT for early assessment of traumatic cerebral contusions. Neuroradiology 50:189-196, 2008

20. Bešenski N, Broz R, Jadro-Šantel D, Pavić D, Mikulić D: The course of traumatising force in acceleration head injury: $C T$ evidence. Neuroradiology 38:36-41, 1996 